\title{
Reflexões acerca do embate entre modernidade e pós-modernidade no âmbito educacional
}

\begin{abstract}
Resumo
Enquanto se baseia na desregulamentação e especialização, a perspectiva pós-moderna lança importantes desafios para o processo formativo, sobretudo por este continuar fundamentado, em parte, em parâmetros metafísico-teológicos de formação. Contudo, frente a esse panorama, é impossível levarmos adiante uma perspectiva formativa embasada apenas em um dos extremos: não nos é possível romper com a tradição e assumir a perspectiva de desconstrução da cultura e de tudo o que o homem já erigiu, nem tampouco seguir inquestionavelmente os princípios de uma modernidade em crise, como a verticalização e autoritarismo que permeiam as relações de ensino-aprendizagem. A saída para a questão educacional pode estar na perspectiva de uma razão dialógica, a qual possa contrabalancear as mudanças do presente com a obrigatória fundamentação no solo firme da tradição, para assim construir criticamente bases comuns para a ação humana.
\end{abstract}

Palavras-chave: Pós-modernismo. Formação. Razão dialógica.

\section{Para citar este artigo:}

BARONI, Vivian. Reflexões acerca do embate entre modernidade e pós-modernidade no âmbito educacional. Revista Linhas. Florianópolis, v. 20, n. 44, p. 305-325, set./dez. 2019.

\author{
Vivian Baroni \\ Universidade de Passo Fundo - UPF \\ - Passo Fundo/RS - Brasil \\ vivianbaroni@hotmail.com
}




\title{
Reflections on the embating between modernity and post- modernity in the educational sector
}

\begin{abstract}
While based on deregulation and specialization, postmodern perspective sheds important challenges for the educational process, especially for continuing based partly on metaphysical and theological parameters of training. However, against this background, it is impossible to carry on with an informed formative perspective only at one end: we cannot break with tradition and take the deconstruction perspective of culture and everything that man has ever erected, nor follow unquestionably the principles of modernity in crisis, such as vertical integration and authoritarianism that permeates the teaching-learning relationships. The output for educational issue may be from the perspective of a dialogical reason, which can offset the changes of this with the mandatory basis on the firm ground of tradition, so as build critically common basis for human action.
\end{abstract}

Keywords: Post-modernity. Formation. Dialogic reason. 


\section{Introdução}

O que significa formar novas gerações em um contexto marcado por formas pósmetafísicas de pensamento, entrelaçadas com traços metafísico-teológicos de formação humana? Em meio às transformações que se operam na sociedade, a educação se vê confrontada com novos paradigmas nos campos do conhecimento e das relações sociais que, ao mesmo tempo, se imiscuem com elementos marcadamente tradicionais. Dessa maneira, torna-se impossível basear a prática educativa em critérios de certeza: já não é mais possível orientar um ideal formativo sob os parâmetros da verticalidade das relações pedagógicas, nem tampouco no princípio da autoridade docente. Ou seja, o amparo na tradição per se já não é capaz de solucionar os problemas que se originam de uma nova configuração da realidade no esquema da pós-modernidade.

Nesse sentido, os processos vivenciados pelas sociedades complexas devem ser compreendidos em toda a sua especificidade e multiplicidade, o que só pode ser alcançado corretamente por meio de uma abordagem dialética da realidade. Trata-se de realizar um apropriado diagnóstico de época que leve em consideração a contradição como mola propulsora da dinâmica social, assim como parâmetro central das transformações em curso. De um lado, é preciso reconhecer que a sociedade está passando por transformações substanciais tanto nas esferas sociais quanto mercadológicas e trabalhistas, e que afetam diretamente a educação como um todo. Por outro lado, é preciso considerar que a educação em sua esfera institucional ainda baseia a sua prática essencialmente em parâmetros metafísico-teológicos.

No presente artigo, de caráter eminentemente teórico, pretendemos investigar as consequências de um processo formativo marcado pelas transformações características da pós-modernidade, embora ainda embasado fundamentalmente em traços metafísicos. Pretendemos, ainda, problematizar as possíveis alternativas de um modelo de educacional que não se deixe levar meramente pelo novo, nem abandone as suas pretensões emancipatórias na autoridade e no verticalismo metafísico. Contudo, não é nosso objetivo estabelecer uma abordagem sistemática dos temas referentes à pósmodernidade, mas, a partir de um ponto de vista sinótico, confrontar os princípios educacionais subjacentes à modernidade e à pós-modernidade e, a partir disso, vislumbrar possíveis alternativas para o campo da educação. 
Para tanto, desenvolvemos a nossa argumentação em três momentos distintos. Primeiramente, traçamos um sucinto apanhado geral das principais tendências que caracterizam a chamada pós-modernidade, destacando a sua influência sobre a concepção de conhecimento. A consequência imediata é a classificação do conhecimento através de modelos informacionais que, dessa maneira, ficam restritos aos critérios de desempenho. Na segunda parte, procuramos caracterizar os processos formativos no interior desse panorama de transformações e marcado pela mercantilização da educação. Por fim, na terceira parte, refletimos acerca das atitudes e elementos que podem auxiliar na superação da crise gerada por esse panorama, que se centram no resgate do diálogo com a tradição passada.

\section{Pós-modernidade: traços característicos}

A crise da modernidade foi tratada de diversas maneiras e sob vários enfoques. Weber define a modernidade como ‘desencantamento do mundo'; Nietzsche, Heidegger, Adorno, Horkheimer e Foucault, cada um a seu modo, também tratam da temática do “desencantamento" da modernidade. As discussões desse grupo de autores partem da problematização levantada pelas falhas do projeto iluminista, incapaz de consumar seus objetivos. Mais tarde, entram em cena autores que investigam os traços característicos da contemporaneidade, marcada por sociedades que se complexificam cada vez mais mediante processos internos de diferenciação e pelo alto dinamismo presente em todas as suas dimensões. Nesse sentido, Lypovetsky (2004) fala de 'tempos hipermodernos'; Beck (2011) se refere à 'sociedade de risco'; Habermas (1993) problematiza uma 'neomodernidade' ou 'capitalismo tardio'; Bauman (2001) chama essa nova tessitura da sociedade de 'modernidade líquida'; Giddens (1991), de 'alta modernidade'; e Lyotard (2000), de 'pós-modernidade'.

A leitura particular de Lyotard (2000) pode ser considerada a mais polêmica, já que, partindo das teses foucaultianas, realiza uma releitura dos traços centrais da contemporaneidade, reconhecendo nela traços que podem conformar uma nova fase histórica que substitui a modernidade: a pós-modernidade. A centralidade da abordagem de Lyotard está no seu diagnóstico da crise dos metarrelatos: "ao desuso do dispositivo metanarrativo de legitimação corresponde especialmente a crise da filosofia metafísica, e 
da instituição universitária que dependia dela" (LYOTARD, 2000, p. 10). Nesse sentido, o descrédito ao mecanismo metanarrativo e à noção da história como um desenvolvimento e progresso contínuo dão vasão a um colapso geral das instituições basilares da modernidade.

Existe uma incredulidade com relação aos metarrelatos centrais da modernidade, os quais se mostram impossíveis de serem levados a cabo, ou incondizentes com a multiplicidade dos novos papéis sociais. A função narrativa perde suas características: o grande herói, o grande propósito, os grandes perigos, se dispersam em nuvens de elementos narrativos "cada um deles vinculando consigo valências pragmáticas sui generis" (LYOTARD, 2000, p. 10). A pluralidade das narrativas, somando-se à multiplicidade de vivências e identidades em que cada indivíduo se envolve diariamente, faz com que não possamos formar combinações linguísticas estáveis, e as propriedades das que formamos não são necessariamente comunicáveis.

O núcleo do paradigma pós-moderno reside no reconhecimento de que o mundo somente pode ser apreendido através de discursos que o interpretem. Baseando-se nesse paradigma, o conhecimento do mundo social é mais resultado da interação de certos jogos de linguagem, do que instrumento de controle e facilitação da direção pela qual deve seguir o progresso social. Para esse paradigma, a modernidade deixou de ser um discurso sob o qual se podia embasar um projeto de ação social, dissolvendo-se na multiplicidade de discursos particulares, incapazes de projetar uma imagem objetiva das coisas (GOERGEN, 2005). A ênfase do projeto pós-moderno foca-se no local, no particular e no contingente, enquanto a modernidade embasava-se essencialmente no universal, no coletivo e na tradição.

Dessa maneira, a sociedade se move mais em função de uma pragmática de partículas linguísticas do que de uma antropologia newtoniana. A multiplicidade dos jogos de linguagem constitui uma heterogeneidade de elementos, que não se coaduna com a rigidez dos traços principais da metanarrativa moderna. Essa tese influenciou uma série de polêmicas com relevantes implicações teóricas em diversos campos do conhecimento, principalmente para a epistemologia e a filosofia. Contudo, outros campos ditos teórico-práticos tais como a ética e a educação, foram intensamente 
afetados por esse debate, sendo extremamente relevante retomarmos as implicações dessa discussão para o campo educacional.

As mudanças essenciais nas sociedades complexas contemporâneas, que permitiram aos autores citados anteriormente vislumbrarem mudanças estruturais centrais, afetaram a sociedade como um todo, mas de forma especial a relação que os indivíduos mantêm com a informação e o conhecimento. Resumidamente, neste ponto específico, pode-se entender por pós-moderno o estado da cultura posterior às transformações que, nas sociedades desenvolvidas do século XX, afetaram os critérios de verdade que regulavam o fazer científico, filosófico e artístico na modernidade. Ou seja, trata-se de um questionamento da legitimação dos valores que regularam a sociedade na modernidade, como a confiança na razão e o poder da tradição. Frente às novas condições sociais e econômicas, como a desregulamentação dos mercados, a reorganização do conhecimento em critérios cibernéticos e a liquidez dos relacionamentos sociais, é possível reconhecer uma realidade cada vez mais afastada da influência da tradição.

Para Lyotard (2000), o conhecimento muda seu estatuto na medida em que as sociedades entram na chamada era pós-industrial e, as culturas, na pós-modernidade. Já que, segundo as percepções pós-modernas, o saber científico não passa de uma classe de discurso, no sentido da linguagem, a consequência imediata é que ele passa a ser afetado pelas novas formas de circulação da informação. Para Lyotard a multiplicação da organização do conhecimento científico, para que se torne traduzível na linguagem específica da informática, afeta e afetará a circulação dos conhecimentos tanto quanto foi o desenvolvimento dos meios de circulação de pessoas (transporte), de sons e imagens (mídia).

Nesse amplo cenário de transformações, a concepção de ciência sofre uma mudança drástica: prisioneira do saber informático, se reduz a uma modalidade de organização do conhecimento, ou seja, à uma maneira de organizar, armazenar e distribuir informação. O conhecimento acumulado pela humanidade se reduz a partículas fragmentárias que são organizadas de maneira sistemática, excluindo a dimensão histórica, ética e moral desse conhecimento. Nesse sentido, a forma com a qual as tecnologias da informação lidam com o conhecimento, mais do que representar um 
simples avanço no desenvolvimento da técnica, definem uma virada conceitual drástica. Elas introduzem um novo sistema simbólico que reorganiza o sistema simbólico dos seus usuários, impondo outro modelo de existência, modificando hábitos e crenças e conformando elementos estruturantes das relações sociais. Controlar a realidade por meio da tecnologia significa também controlar as instâncias éticas, jurídicas e políticas da sociedade.

Esse é o procedimento mediante o qual toma forma a legitimação do poder: o bom desempenho se erige como critério de verdade da ciência e os mesmos fundamentos qualificam os componentes morais e políticos. Os setores da pesquisa que não contribuem direta ou indiretamente para a otimização do desempenho perdem o interesse dos financiadores, são abandonados e seus temas passam à obsolescência. Para Lyotard (2000), com essa transformação geral, a natureza do saber não fica intacta. Como somente o conhecimento passível de converter-se em operacional pode passar pelos canais operacionais, todo o saber não traduzível é deixado de lado, e a orientação das novas investigações se subordinará à condição de traduzibilidade dos resultados à linguagem da máquina.

Partindo dessa premissa, pode-se compreender a crescente desvalorização sofrida pelas ciências humanas e pelas artes em geral, já que representam dimensões normalmente avessas ao quantificacionismo e à competição irrefreada que permeiam as demais esferas do conhecimento. Como disciplinas marcadas pela concepção histórica e orientadas pela tradição, as ciências humanas carregam ainda os elementos ético e moral que impossibilitam que sobre eles se trabalhe de maneira neutra ou superficial. Uma segunda consequência se refere à mercantilização desses conhecimentos: tornam-se objeto de venda e troca, como qualquer outro produto do mercado. A implicação direta desse panorama é a criação de uma falsa neutralidade em torno do que se convém chamar conhecimento, já que por detrás da fachada de imparcialidade, escondem-se interesses políticos bem definidos.

Na leitura de McLaren (1993), a pós-modernidade pode ser vista como uma época de ruptura, na qual as fronteiras culturais e epistemológicas estão se desfazendo, tornando os gêneros disciplinares cada vez mais indistintos. O autor interpreta a pósmodernidade como um ataque direto à metafísica através da valorização de um discurso 
que se embasa no caráter histórico, imprevisível e não teleológico dos discursos locais e particulares, proferidos de uma posição completamente descolada da tradição. Para tanto, a pós-modernidade representa uma ruptura cultural e epistemológica com a modernidade que fracassou na tentativa de construir indivíduos autônomos capazes de superar a alienação.

É necessário ressaltar ainda que a perspectiva pós-moderna não questiona a legitimidade de uma ou outra forma de ordenamento social, mas sim os próprios fundamentos da legitimação, a própria fundamentação de todo e qualquer sistema social em parâmetros orientadores. Segundo Goergen (2012), o que os pós-modernos questionam é a pretensão do projeto moderno em dominar intelectualmente a pretensão de um fundamento racional ao curso da história. Nesse sentido, está em jogo não somente um questionamento com relação aos parâmetros da modernidade, mas a própria possibilidade de se pensar projetos de desenvolvimentos no curso da história, como projeto de emancipação humana. Se essa possibilidade for eliminada, cabe questionar como será possível legitimar um projeto educacional.

Contudo, a nossa posição frente à pós-modernidade não é a de negar, em princípio e de forma geral, as suas teses, mas sim analisá-las criticamente com o objetivo de compreender as mudanças essenciais no universo social, as quais são evidentes demais para serem ignoradas. A perspectiva pós-moderna é capaz também de nos provocar uma revisão das teses da modernidade, permitindo-nos aproveitar aspectos de suas críticas que desvelam traços aporéticos da racionalidade iluminista, ajudando a compreender algumas tendências do desenvolvimento histórico. De outro lado, defender uma filosofia da história não é o mesmo que atrelar-se à uma ontologia social que conduz necessariamente a um futuro melhor. Significa apenas reconhecer a necessidade de um projeto histórico que aponte como ponto de referência e condição de progresso. 


\section{Educação no contexto pós-moderno}

É necessário ressaltar que a desregulamentação e fluidez, característicos de um panorama pós-moderno, convivem ao mesmo tempo com resquícios fortemente enraizados de uma herança metafísica. No âmbito especificamente educacional, essas diferenças se acentuam, fazendo com que o ensino assuma traços declaradamente contraditórios. Coexistem, no mesmo ambiente educacional, uma noção de conhecimento que se caracteriza pela intensidade, variedade e especialidade e, ao mesmo tempo, com traços marcadamente metafísicos, como a verticalização das relações de ensino-aprendizagem e o rigor metodológico. Nesse sentido, pode ainda haver um agravamento das tensões no ambiente de ensino, já que os estudantes vêm de uma realidade pautada nos pressupostos pós-modernos, enquanto que a educação formal ainda é regida principalmente por traços metafísico-teológicos de formação. Ainda que os pós-modernos falem da modernidade como algo pertencente ao passado e deslegitimado pelas mudanças contemporâneas, é preciso considerar que é sobre os fundamentos dessa ordem ou dessa perspectiva que até hoje baseiam os pressupostos inominados do discurso e da prática educativa.

Torna-se urgente ainda, analisar criticamente o fato de que a aceitação irrestrita das linhas gerais da pós-modernidade pode trazer graves consequências para o campo formativo. Primeiro, o conhecimento, ao ser restrito ao informacional, passa a se orientar por critérios totalmente desligados da dimensão ética e moral, além da exclusão completa do estético e do sensível. Segundo, a mercantilização do saber faz com que a esfera formativa institucional passe a ser regida unicamente pela via do mercado, seguindo suas regras e se submetendo às suas exigências: o lucro torna-se o único resultado a ser alcançado pelas instituições educativas e pelos indivíduos que nela procuram formação. Supondo que o projeto moderno considerasse o conhecimento como elemento principal com o qual seria possível aos indivíduos alcançar a autonomia e o livre desenvolvimento, devemos agora questionar o que acontece com esse ideal num momento em que a educação passa a se colocar a serviço do sistema, da economia e do mercado. 
O resultado imediato dessa dinâmica é o encurtamento drástico da formação, que de formação ampla, como apregoado pelos modelos clássicos da Paideia ${ }^{1}$ e da Bildung ${ }^{2}$, passa a se dirigir para a formação do sujeito econômico: aquele que tem por meta a inclusão lucrativa e eficiente no mercado de trabalho. A consequência da aceitação dos pressupostos da pós-modernidade será que a educação deve abandonar todas as suas preocupações formativas canalizadas para a formação de cidadãos dispostos a assumirem a responsabilidade de construção de um mundo melhor. Depois da grande revolução informática, a questão da habilidade técnica tornou-se central. Além dos conhecimentos necessários para a inserção na sociedade, o educando deve adquirir capacidades para se mover em um cenário caótico e desdiferenciado, aprendendo a reconhecer as questões fundamentais para o sujeito, para a vida e para conivência social. O problema se resume a como fazer tudo isso no interior de um contexto caracterizado pela ausência de princípios norteadores.

Para Goergen (2012) as consequências da aceitação da racionalidade utilitarista provocam uma profunda crise epistêmica que aponta essencialmente para a retomada de questões relativas ao sentido humano, social e moral do conhecimento. Nesse sentido, entram em pauta temas como a discussão sobre o aspecto ético das pesquisas científicas, a agressão ao meio ambiente, o uso de energia nuclear e a manipulação genética. A partir desses temas, pode-se inferir que o que está em jogo é o próprio modelo de conhecimento e seu sentido humano. Com a invasão crescente de uma tecnologia aparentemente neutra com relação a valores no âmbito do universo social, corre-se o risco de que o conhecimento perca de vista o seu caráter essencial de possibilitar uma melhoria qualitativa de vida aos indivíduos.

O desenvolvimento dos currículos de formação embasados nos critérios de eficiência e eficácia favoreceu uma formação que prima pela especialização e refinamento metodológico. Sob essa perspectiva, a escola acaba se focando em uma formação mais pragmática, deixando de lado aspectos não rentáveis do currículo, como

\footnotetext{
1 Conceito grego que abrange o significado e as implicações da formação para o cidadão grego. Compreendia uma formação ampla: todas as manifestações artísticas, culturais, intelectuais e religiosas compunham a Paideia grega.

${ }^{2}$ A tradução alemã para o conceito de Paideia. Surgido com o idealismo alemão, o conceito de Bildung carrega consigo o sentido de uma formação harmônica e ampla, incluindo o desenvolvimento estético, moral e intelectual dos indivíduos.
} 
as artes e a filosofia, mas que são extremamente relevantes no contexto da formação do cidadão. Como subsistema de um sistema social dado, a escola também adota o desempenho por critérios de pertinência, funcionando como fornecedora de quadros úteis às instituições pragmáticas. Usando-se desse mecanismo de forma acrítica, a escola se subordina ao poder. Todo o saber não conversível ao saber aplicado ou técnico é descartado, o que muda o rumo do ensino, da mesma forma como mudou o rumo da ciência. O progresso da ciência, ao contrário, não se faz graças ao positivismo da eficiência, mas por um caminho muito diverso: trabalhar para provar uma hipótese é pesquisar, inventar hipóteses contrárias, propor o inteligível.

Para Dalbosco (2010), as transformações ocorridas no universo do trabalho e das relações mercantis que os caracterizam assumem novas feições no mundo contemporâneo, configurando uma nova tessitura de relações sociais e exigindo uma reconfiguração da identidade e do papel assumido por muitas instituições. Nesse sentido, com a mudança no mundo do trabalho, a própria universidade passou a sofrer mudanças fundamentais (PANIZZI, 2006). Isso transparece na nova configuração dos cursos, a maior procura por cursos noturnos em relação aos de tempo integral, a diminuição do tempo de formação, a redução dos créditos obrigatórios e o aumento da demanda na universidade privada.

Para Santos (1989, 2004), a universidade está passando por uma tríplice crise: de hegemonia, de legitimidade e institucional. A crise da hegemonia resulta das contradições entre as funções tradicionais da universidade: de um lado, a produção da alta cultura, pensamento crítico e conhecimentos científicos e humanísticos necessários à formação das elites; de outro, a produção de padrões culturais médios e conhecimentos instrumentais necessários à formação de mão de obra qualificada para o mercado capitalista. A crise da legitimidade foi provocada pelo fato de a universidade ter deixado de ser uma instituição consensual em face da contradição entre a hierarquização dos saberes, por um lado, e as exigências sociais e políticas da democratização da universidade, por outro. A crise institucional, por sua vez, se refere à contradição presente na reivindicação da autonomia na definição dos valores e objetivos da universidade, enquanto convive com a pressão constante de submeter esta última a 
critérios de eficácia e produtividade de natureza empresarial ou de responsabilidade social.

Para Santos (1989 as múltiplas crises pelas quais a universidade passa são afloramentos diretos da tensão do paradigma da modernidade, sendo que a crise desta só pode ser superada no contexto de resolução da própria queda da modernidade. Isso porque, a partir do momento em que a racionalidade que sustentava o modo de ser da universidade entra em colapso, a própria instituição vê a sua estrutura básica posta em questão:

A ideia da unidade do saber universitário foi sendo progressivamente substituída pela hegemonia da racionalidade cognitivo-instrumental e, portanto, da ciência da natureza. Estas representam, por excelência, o desenvolvimento do paradigma da ciência moderna. A crise deste paradigma não pode deixar de acarretar a crise da ideia de universidade moderna. (SANTOS, 1989, p. 51)

Dalbosco (2010) se refere à especialização do conhecimento como um aspecto marcante da contemporaneidade. Para o autor, coexistem aqui duas tendências básicas: por um lado, há uma multiplicação da pesquisa e, com ela, o surgimento das mais variadas áreas do saber, o que resulta em um conhecimento cada vez mais especializado. Essa configuração do conhecimento exige, por sua vez, a criação de grupos de trabalho reunindo profissionais de áreas diferentes, o que aponta para a internacionalização da educação e da pesquisa como um traço característico das sociedades avançadas. Ao mesmo tempo, a informação, motivada pela ampliação do alcance e acesso através da informática, torna-se característica central da sociedade, influenciando decisivamente os setores mercadológicos, sociais e formativos. Na perspectiva de uma valorização apenas dos conhecimentos traduzíveis em linguagem informática, Lyotard aponta para a tendência ao rechaço da formação em seu sentido clássico:

O antigo princípio da aquisição do saber, que é indissociável da formação (Bildung) do espírito, e inclusive da pessoa, cai em desuso. Essa relação dos provedores e dos usuários do conhecimento com o saber tende a e tenderá cada vez mais a revestir a forma que os produtores e consumidores de mercadoria mantém com essas últimas, ou seja, a forma valor. O saber é e será produzido para vender, e é e será consumido para ser avaliado em uma nova produção: nos dois casos para 
ser trocado. Deixa de ser em si mesmo seu próprio fim, perde seu "valor de uso". (LYOTARD, 2000, p. 16, tradução nossa)

Contudo, andando lado a lado com essa tendência progressiva, a especialização, a celeridade e a rapidez da informação fazem com que o conhecimento fique restrito a um único segmento, o que gera fragmentação e impede o diálogo entre as disciplinas. 0 reflexo disso se faz sentir principalmente nas disciplinas chamadas técnicas, nas quais a formação mais ampla, integrando o técnico às dimensões ética, estética e moral é são deixadas de lado, resultando em uma formação deficiente. O risco que se corre aqui é trocar um conceito amplo de formação, por uma semiformação (ADORNO, 1996), que chega a ser pior do que formação nenhuma, já que elimina completamente a reflexão e a crítica, excluindo da esfera da ação os critérios éticos e morais do agir humano. Nessa perspectiva de especialização dos conhecimentos, da tomada de decisões longe da solidez da tradição, torna-se sem sentido refletir sobre questões que busquem trabalhar o significado de formação ou a importância e o papel da universidade.

Dalbosco (2010) chama atenção, ainda, para a política governamental adotada nas últimas décadas no âmbito do ensino superior. Inserida em decorrência da enorme demanda, criou-se uma política expansionista e desregrada que se espelha no modelo de ensino privado ou empresarial. Tal fato gerou uma competição desleal com outras instituições, como as comunitárias, que impossibilitadas de competir com os preços reduzidos das instituições privadas, se viram em graves crises financeiras. Além disso, a mercantilização do ensino superior gera também uma formação nos moldes do mercado, ou seja, marcada pela competitividade e desrespeito aos aspectos não "rentáveis" da formação, como aqueles em que se pautam as ciências humanas. Dentro desse esquema, o que está em jogo é o próprio conceito de formação, já que a mercantilização da educação não traz a necessidade de se pensar a educação a partir de tradições teóricas sólidas. Nesse contexto, é preciso questionar se esse processo de mercantilização da educação pode ser devidamente controlado pela avaliação, impedindo previamente a consequente perda de qualidade. Mais ainda, é necessário interrogar como a educação se dá nessa estrutura massiva e excessivamente especializada. Quanto ao constante apelo à profissionalização, poderíamos argumentar: especializar para quê? E para quem? 
A educação superior marcada por esses moldes acaba fatalmente por refletir seus princípios nas práticas de pesquisa, inclusive na pesquisa educacional. Isso é o que mostra o crescimento do movimento de pesquisas científicas baseadas em evidências. Para Chizzotti (2015), a migração de técnicas das empresas privadas para as universidades ao privilegiar o interesse instrumental, destrói as motivações que são intrínsecas à pesquisa, como a criatividade e a originalidade dos processos inventivos em favor do prestígio, poder e vantagens. Existe um discurso produzido por áreas que supõe deter competência gerencial de recursos financeiros e humanos, prescrevendo medidas mesuradas de sucesso para a educação. A crítica desse campo à educação foca-se na acusação de falta de rigor científico e pouco valor prático para resolver os problemas de forma imediata. Para tanto, propõe-se que as pesquisas educacionais sigam os modelos das ciências quantitativas para elevar ao nível científico.

Deve-se destacar, ainda, o aspecto que diz respeito ao perfil do egresso na universidade que, por sua vez, poderá se tornar um futuro docente. Crescendo dentro de um contexto sociocultural marcado pelo predomínio de uma cultura imagética, as implicações para a formação das capacidades cognitiva, estética e moral das novas gerações precisam ser mais bem investigadas. Junto a isso, soma-se a impotência da educação formal, da qual escapam contingentes cada vez maiores de analfabetos funcionais. O que argumentam os defensores da perspectiva pós-moderna na educação, é alcançar um novo padrão de qualidade pela via da desregulamentação e privatização, implicando com isso a não obrigatoriedade da educação até determinada idade e a eliminação de um grau mínimo de controle pelo Estado. Contudo, o único resultado que pode ser esperado ao adotar essa perspectiva é o de que a escola torne-se uma instituição e a educação um produto: a educação se transforma em mercadoria e, dessa maneira, fica sujeita às leis do mercado. Nisso, perde-se a sua faceta humana essencial (GOERGE, 2005, p. 76).

Assim, a educação afasta-se cada vez mais de uma formação do sujeito em sua totalidade, que objetivava trabalhar os aspectos morais, éticos e estéticos em consonância com um projeto emancipatório com vistas para o coletivo. Para Dalbosco (2010), a consequência mais palpável desse contexto é a impossibilidade das gerações mais novas levarem adiante um diálogo vivo e criativo com a tradição cultural passada. 
Nesse sentido, pode-se dizer que "quanto mais a cultura contemporânea movimenta-se na direção do conhecimento e da informação virtual, mais as novas gerações mostram-se despreparadas para a construção de referenciais crítico-interpretativos sólidos e consistentes" (DALBOSCO, 2010, p. 117). Logo, não é possível construir referenciais formativos sólidos desligando-se da história e dos metarrelatos modernos, pois assim, também abandonaríamos toda fundamentação ética do agir humano que brota da tradição.

\section{Alternativas formativas no contexto pós-moderno}

Frente ao panorama sombrio que se apresenta, não é possível aceitar passivamente os pressupostos de uma sociedade desregulamentada, nem o fim da história, como o faz Lyotard, caindo em uma visão dualista da realidade. Para Goergen (2005), a crítica aos metarrelatos implica uma negação tout court da ideia de progresso histórico para a construção de uma sociedade melhor através do uso da razão, conforme está inscrito no âmago do projeto moderno, deixando de lado todo o conhecimento acumulado pelas gerações passadas. Nesse esquema, perde sentido pensar a educação a partir de uma perspectiva emancipatória, já que os referenciais éticos, estéticos e racionais se perdem na dinâmica sempre constante da mudança.

Contudo, é exatamente pela impossibilidade de se basear uma ética na celeridade que o amparo na tradição passada torna-se referência essencial para se compreender esse novo paradigma. Vale ressaltar que esse recurso à tradição não deve estar amparado nas dimensões metafísico-teológicas marcadas pelo dogmatismo. O diálogo com a tradição deve vir movido pela necessidade de compreender o presente sob novas perspectivas, permitindo com isso uma problematização dos desafios lançados por este. Com isso, abre-se a possibilidade de vislumbrarmos horizontes emancipatórios para o presente a partir de uma visão que contemple os aspectos contraditórios da realidade em um sentido dialético.

Ainda que seja tarefa da educação formar sujeitos capazes de se inserir na sociedade, assim como provê-los de capacidades básicas que lhes permitirão participar do mercado de trabalho, a formação em um sentido amplo não pode estar restrita a esse 
âmbito somente. Compete também à educação conduzir as jovens gerações no sentido de sensibilizá-las para o problema da ética como fundamento da vida humana na sua relação com a natureza, com os outros seres humanos e consigo mesmas. É preciso que a educação ajude a formar as competências para que os jovens saibam participar desse processo de formação como parte integrante da constituição e fortalecimento da vida em comum, ou seja, da sociedade como um todo. "O preço que a escola paga pela submissão acrítica aos ditames da razão instrumental é a perda da dimensão ético-política do projeto histórico de emancipação" (GOERGEN, 2005, p. 83).

Para fazer frente a esse panorama, Dalbosco (2010) afirma que somente um conceito pós-metafísico de razão é capaz de pôr em questão a ideia da formação e ampliá-la por meio do resgate de aspectos do seu sentido clássico, o que a torna mais apta e operante para enfrentar os desafios atuais. A complexificação social e a especialização do conhecimento inviabilizam a posição metafísica (kantiana) da filosofia como indicadora de lugar. Sob esse viés, pode-se afirmar que o problema reside na própria noção de filosofia e na necessidade de sua transformação pós-metafísica. De acordo com a opinião de Habermas, não cabe mais à filosofia a condição de guardadora de lugar da racionalidade, a ela cabe agora a função de intérprete da cultura. E é exatamente essa modificação do lugar da filosofia que permite a sua saída de uma posição metafísica para a posição pós-metafísica.

Contudo, o problema mais sério, e que se reflete diretamente na questão da formação docente, é que "a metafísica moderna está baseada em um modelo representacional e dicotômico de conhecimento, concebendo-o como resultado da relação entre o sujeito cognoscente e o objeto a ser conhecido" (DALBOSCO, 2010, p. 121). Essa noção sustenta a concepção pedagógica tradicional do conhecimento como passível de transmissão, indicando ainda uma relação pedagógica verticalizada, marcada pela primazia do professor como detentor do conhecimento. Nesse esquema, a formação é vista como um objeto a ser apropriado e, de posse desta, o profissional docente estaria, então, pronto para educar os outros.

Contudo, esse conceito de formação ignora tanto a ideia de formação continuada, como a questão da maneira como se ensina e se aprende. A educação faz parte de um processo que necessariamente deve incluir a interação recíproca dos envolvidos, 
afetando da mesma maneira alunos e professores. Voltando-se à filosofia habermasiana, Dalbosco (2010) ressalta a importância de se pensar um conceito de razão que abarque a dimensão linguística em relação direta com a ação, devendo existir uma relação de cooriginalidade entre a razão e os processos linguísticos. Dessa maneira, a constituição de si mesmo ocorre não mais em referência à manipulação de algo externo ao sujeito, mas sim pela consideração da sua potencialidade linguístico-interativa.

A teoria da ação comunicativa desenvolvida por Habermas (1989) procura refundamentar o conceito de verdade a partir do processo comunicativo. Nesse sentido, a ética do discurso assenta-se sobre os pressupostos transcendentais do agir comunicativo, voltando-se essencialmente para o entendimento mútuo. Assim, Habermas afirma que o agir humano não é completamente resultado de nossa escolha, logo, qualquer um que aceite participar da prática educativa deve também ter aceito os pressupostos inominados do discurso. A consequência mais direta da teoria da ação comunicativa diz respeito ao esforço de resgatar um conceito comunicativo de razão no qual os atores do processo são diretamente conscientes e responsáveis por suas ações. Outro ponto central é o de que todos os valores e normas vigentes na sociedade são discutidos e tematizados coletivamente através de várias perspectivas, buscando alcançar um consenso sobre os pontos válidos (GOERGEN, 2005).

Dessa maneira, a teoria da ação comunicativa busca fazer frente à tese pósmetafísica da explicação do mundo através de partículas fragmentárias de discursos, demonstrando a possibilidade e necessidade de se construírem discursos dialeticamente produzidos que atuam com base no princípio da interação mútua.

Essa concepção linguística de razão, implica também pensar um conceito de razão destranscendentalizada, ou seja, uma razão constituída histórica e socialmente. Assim, podemos vislumbrar também as contribuições da crítica pós-moderna às ideias cristalizadas da modernidade. Essa possibilidade conduz diretamente, do ponto de vista epistemológico, à desobjetificação da relação entre sujeito e objeto, e do ponto de vista pedagógico, à desverticalização da relação entre sujeitos. Na relação formativa, portanto, essa perspectiva aponta para o "questionamento da posição autoritária e arrogante daquele professor que se coloca na condição de alguém que somente ensina" (DALBOSCO, 2010, p. 126). A ação baseada no diálogo, longe de desautorizar o professor, 
aponta para uma relação entre sujeitos mediada pela linguagem, na qual, por meio de sua competência comunicativa, desenvolvem entre si processos recíprocos de aprendizagem. Ultrapassando a noção verticalizada de pedagogia, surge, ao mesmo tempo, a necessidade de formação permanente, que se associa à ideia de que o próprio profissional precisa se atualizar constantemente, o que o exige colocar-se na posição de permanente aprendizagem.

O certo é que precisamos, de uma vez por todas, descartar toda e qualquer esperança de retornarmos a um passado metafísico, transcendentalista e autoritário, quando todo o contexto contemporâneo aponta para o questionamento dessa dimensão, marcadamente dogmatista. Ao mesmo tempo, é preciso considerar que o indivíduo não nasce no vazio, apartado da cultura, que apesar de tudo tem suas bases fixas na tradição passada: “o passado, ou a cultura podem ser trabalhados, tematizados, assumidos ou parcialmente rejeitados, mas com eles não podemos simplesmente romper como num passe de mágica" (GOERGEN, 2005, p. 79). Dessa forma, a educação não deve ser uma introdução dos jovens em um mundo eterno de valores, definidos e impostos, nem um espaço vazio de valores. O objetivo da educação deve ser trabalhar a tradição criticamente a fim de construir bases comuns para a ação.

Para Habermas (1990), ao contrário da visão destrutiva representada pela pósmodernidade, a racionalidade moderna não pode ser completamente invalidada pelo fracasso dos seus ideais emancipatórios. O núcleo da tese de Habermas centra-se na consideração de que sem um metarrelato forte que se subtraia à dissolução do histórico, o fim da história não é possível. Para tanto, a tradição ainda apresenta um traço forte na constituição da cultura, conformando ainda a educação como um processo sociocultural de interação que se substancializa no diálogo das novas gerações com a tradição passada. 


\section{Considerações finais}

Não há como negar que as sociedades complexas de hoje passam por mudanças estruturais essenciais que afetam profundamente a esfera educacional. Vemos surgir uma cultura informática e imagética, marcada pela desregulamentação e especialização, que bate de frente com o verticalismo do conhecimento que advém da tradição moderna. Ambas as perspectivas possuem traços tanto positivos quanto negativos, sendo-nos impossível resolver os problemas da contemporaneidade meramente através da escolha de um lado, modernidade ou pós-modernidade, Habermas ou Lyotard, apocalípticos ou integrados. O caminho para se pensar um projeto formativo em um contexto de transformações não passa pela defesa a qualquer custo da tradição moderna, nem tampouco deve aderir acriticamente à desconstrução de tudo o que o homem e a sociedade construíram ao logo dos séculos, como prega a pós-modernidade. A única saída parece ser a posição afirmativa dos educadores de se inserirem criticamente no debate entre essas duas perspectivas, para, a partir daí, construir em consonância com o coletivo os princípios que possam orientar a prática educativa.

Se, por um lado, o descolamento das normas, a liquidez das relações sociais e a necessidade de reinvenção constante do novo inserem o debate educacional em um cenário pessimista de impossibilidade de uma formação em sentido amplo, possibilita, por outro, que se repense, com a crítica da modernidade, a própria ideia de formação que até agora amparou os pressupostos inominados da prática educativa nos princípios metafísicos-teológicos. A crítica pós-moderna traz consigo toda uma série de implicações ao discurso moderno a partir das quais é possível problematizar aspectos centrais da educação, dando margem para a possibilidade de dirigirmos um outro olhar que tome como ponto de partida o passado em inter-relação direta com o atual. Só assim podemos pensar um conceito de formação que não se abandone meramente ao novo, mas que tenha na tradição um aporte teórico sólido com o qual possa trabalhar criticamente os desafios lançados pelo contemporâneo.

Nesse sentido, a teoria da ação comunicativa de Habermas nos proporciona uma perspectiva dialética para abordarmos de forma satisfatória a questão da pósmodernidade. A ética do discurso assenta sobre o pressuposto da dialogicidade, no qual as normas e valores históricos da humanidade não podem ser considerados, em nenhum 
momento, perenes ou transcendentais, sem, contudo, deixarem de ser universais. O mais importante, nessa perspectiva, é que a proposta de Habermas aponta para o fato de que os valores e normas tradicionais não podem ser descartados, nem tampouco serem considerados inquestionáveis. Logo, permite interpretar e assumir as transformações na perspectiva do processo, e não da ruptura.

Para tanto, o passado deve permanecer enquanto princípio orientador da conduta, já que o ser humano não nasce do vazio, mas do interior de uma determinada cultura que é resultado de uma relação dos homens com o meio e entre si. Nesses termos, seria impossível assumir a perspectiva de rompimento com o passado pois, para isso, teríamos que deixar de ser nós mesmos, influenciados pela cultura. O processo educativo não pode mais ser considerado como a mera introdução dos sujeitos em um universo de valores fixos, nem em um espaço vazio de normas e cultura; é preciso, ao contrário, que a educação seja um processo constante de tematização consciente e ininterrupto da tradição com o objetivo de alcançar bases comuns para a ação.

\section{Referências}

ADORNO, Theodor, W. Teoria da semicultura. Educação e sociedade, Campinas, Editora Papirus, n. 56, ano XVII, dez. de 1996.

BECK, Ulrich. Sociedade de risco: rumo a uma outra modernidade. 2. ed. São Paulo: Editora 34, 2011.

BAUMAN, Zygmunt. Modernidade liquida. Rio de Janeiro: Zahar, 2001.

DALBOSCO, Claudio. Natureza da pesquisa em educação: abrindo o leque de alguns problemas. In: HENNING, Leonir Maria Padilha (org.). Pesquisa, ensino e extensão no campo filosófico educacional: possibilidades presentes no contexto universitário. Londrina: Eduel, 2010, p. 41-66. 
GIDDENS, Anthony. As consequências da modernidade. 5. ed. Trad. Raul Filker. São Paulo: UNESP, 1991.

GOERGEN, Pedro. Pós-modernidade, ética e educação. 2. ed. Campinas, SP: Autores Associados, 2005.

HABERMAS, Jürgen. Consciência moral e agir comunicativo. Rio de janeiro: tempo brasileiro, 1989.

HABERMAS, Jürgen. Pensamento pós-metafísico. Rio de janeiro: Tempo Brasileiro, 1990.

HABERMAS, Jürgen. El discurso filosófico de la modernidad: doce leciones. 4. ed. Madrid: Taurus, 1993.

LYOTARD, Jean-François. La condicion posmoderna. 7. ed. Madri: Catedra Teorema, 2000.

LYPOVETSKY, Gilles. Os tempos hipermodernos. São Paulo: Barcarolla, 2004.

MCLAREN, Peter. Pós-modernismo, pós-colonialismo e pedagogia. In: SILVA, Tomaz Tadeu da. Teoria crítica em tempos pós-modernos. Porto Alegre: Artes Médicas, 1993. p. 9-40.

PANIZZI, Wrana. Universidade para quê? Porto Alegre: Librittos, 2006.

SANTOS, Boaventura de Souza. Da ideia de universidade à universidade de ideias. Revista Crítica de Ciências Sociais, Coimbra, n. 27/28, jun. 1989, p. 11-62.

SANTOS, Boaventura de Souza. Universidade no século XXI. São Paulo: Cortez, 2004.

Recebido em: 13/12/2017 Revisões requeridas: 26/02/2018 Aprovado em: 29/06/2018

Universidade do Estado de Santa Catarina - UDESC Programa de Pós-Graduação em Educação - PPGE Revista Linhas Volume 20 - Número 44 - Ano 2019 revistalinhas@gmail.com 